\title{
PROCESS ENGINEERING IN IRON PRODUCTION
}

\author{
Pavlína Pustějovská ${ }^{1,2}$, Simona Jursová ${ }^{2 *}$ \\ ${ }^{1}$ VŠB - Technical University of Ostrava, Faculty of Metallurgy and Material Engineering, \\ Department of Metallurgy and Foundry, 17. listopadu 15/2172, 70833 Ostrava - Poruba, \\ Czech Republic \\ ${ }^{2}$ VŠB - Technical University of Ostrava, Centre ENET - Energy Units for Utilization of Non- \\ traditional Energy Sources, 17. Listopadu 15/2172, 70833 Ostrava - Poruba, Czech Republic
}

\begin{abstract}
Balance, thermodynamic and mainly kinetic approaches using methods of process engineering enable to determine conditions under which iron technology can actually work in limiting technological states, at the lowest reachable fuel consumption (reducing factor) and the highest reachable productivity accordingly. Kinetic simulation can be also used for variant prognostic calculations. The paper deals with thermodynamics and kinetics of iron making process. It presents a kinetic model of iron oxide reduction in a low temperature area. In the experimental part it deals with testing of iron ore feedstock properties. The theoretical and practical limits determined by heat conditions, feedstock reducibility and kinetics of processes are calculated.
\end{abstract}

Keywords: heat balance, kinetic model, carbon consumption, reducibility

\section{INTRODUCTION}

Heat balance of blast furnace operation has been for many years based on heat supply and heat consumption in the heart of furnace. It is necessary for calculations to determine the composition of top gas or prerequisite of chemical equilibrium between the composition of reductive gas and iron ore feedstock. The procedure of calculation is described in Czech literature in a fundamental text book by Professor Brož (1975).

The theory of counter flow reactors marked a fundamental turning point in chemical engineering. Their application involving blast furnace process was designed by Professor Rist. The so-called Rist's diagram presents a graphic dependence of oxidation grade of the feedstock on oxidation grade of the reductive gas. As it results from the principle of matter conservation, this dependence is described by an operative line whose location is determined by the equilibrium state between iron oxides and reductive gas. The stationary model of oxygen circulation between the feedstock and the reductive gas was designed by Le Corre (1977). The knowledge was followed in former Czechoslovakia by further research activities.

The first laboratory of blast furnace feedstock properties was founded in the department of metallurgical research in iron works at Vitkovice. Ore and agglomerate's reducibility as well as coke reactivity were tested. The development of experimental devices was led by Prouza and Vitek. The laboratory of blast furnace raw materials as blast furnace research were later displaced by a newly established Research Institution of ferrous metallurgy in Dobra. In in the 1970s, the theoretical research in mathematic modelling of direct and indirect reduction begun. A cooperation with Dr. Stanek from 
ÚTZCHT ČS AV (Institute for Theoretical Basic of Chemical Technique, Academy of Sciences, Prague) was initiated Stanek with Moravec designed a mathematical model of indirect reduction describing oxygen circulation between ore feedstock and reductive gas along the isothermal zone of blast furnace shaft. The model included a version for the shaft and for firm bed in the furnace retort for reducibility tests. The variant for the shaft related to numerical solution of differential equations, while differential equations for reducibility tests were written in formulas. Experimental data were provided by Dr. Honza. It was possible to compute a kinetic constant of each reduction grade of iron oxides according to the matter depletion in time. Prof. Tůma (Rist and Meysson, 1964; Tůma et al, 1988) interconnected both the model of indirect reduction and Rist 's model. The established procedure for calculation enabled to predict coke consumption for pig iron production according to laboratory tests of blast furnace feedstock without advanced definitions of top gas composition. The procedure of calculation was verified by Dr. Drabina for many blast furnaces in the former Czechoslovakia. Modelling of the reduction in reductive installation COREX was evaluated by Professor Bilik at VŠB Technical University (Bilik et al., 1998;. Bilik and Schützenhöfer, 1999).

The paper analyses details for renewal of the research in blast furnace process within Faculty of Metallurgy and Material Engineering and Research Centre ENET at VŠB - Technical University of Ostrava. A newly established laboratory for reducibility testing is an impulse to overcome the former limits and renew research into reducibility.

\section{MATHEMATIC MODEL OF INDIRECT REDUCTION IN A COUNTER-FLOW SYSTEM OF REDUCTION STACK}

Practical reduction of metal oxides involves an input of solid or gaseous materials (so-called reducing factors) into a reaction system where they bond oxygen from reduced oxides and oxidise themselves in this way. In metallurgy, reducing factors based on carbon are used first of all because negative Gibbs energy with oxidation reaction of carbon markedly increases with temperature increase. Therefore, carbon reduces the majority of elements and their oxides under conditions of blast furnace, only with the exception of $\mathrm{Ca}, \mathrm{Mg}$ and $\mathrm{Al}$. $\mathrm{CO}$ is also used besides carbon as a reducing factor in the blast furnace under relatively low temperatures.

Oxide reduction proceeds in the following order from oxides with a higher share of oxygen, through oxides with a lower share of oxygen up to elements. In the blast furnace the process occurs largely according to the following scheme:

$$
\mathrm{Fe}_{2} \mathrm{O}_{3} \rightarrow \mathrm{Fe}_{3} \mathrm{O}_{4} \rightarrow \mathrm{FeO} \rightarrow \mathrm{Fe}
$$

It was proved experimentally (Andronov, 2007) that reduction occurs in two ways: by reaction of ore directly with carbon of reducing factor or by interaction with reducing gas. The reduction using $\mathrm{CO}$ resulting in $\mathrm{CO}_{2}$ as a final product is usually referred to indirect reduction, reduction with carbon resulting in $\mathrm{CO}$ is called direct reduction. The sum of direct and indirect reduction represents total reduction. So it is valid:

$$
r_{i}=1-r_{d} \quad \text { and } \quad r_{d}=1-r_{i}
$$

The reaction of hematite is exothermic and irreversible:

$$
3 \mathrm{Fe}_{2} \mathrm{O}_{3}+\mathrm{CO} \rightarrow 2 \mathrm{Fe}_{3} \mathrm{O}_{4}+\mathrm{CO}_{2}+52.85 \mathrm{~kJ}
$$

On the contrary, the reduction of magnetite to wustit and then to metallic iron is a reversible process. Providing that a reduction reaction requires that $\mathrm{CO} / \mathrm{CO}_{2}$ proportion in the gaseous phase would exceed the stechiometric value and that the reactions do not occur in an inverse direction.

$$
\mathrm{Fe}_{3} \mathrm{O}_{4}+\mathrm{m} \mathrm{CO} \rightarrow 3 \mathrm{FeO}+\mathrm{CO}_{2}+(m-1) \mathrm{CO}-36.46 \mathrm{~kJ}
$$




$$
\mathrm{FeO}+\mathrm{n} \mathrm{CO} \rightarrow \mathrm{Fe}+\mathrm{CO}_{2}+(n-1) \mathrm{CO}+17.13 \mathrm{~kJ}
$$

Iron oxides react with reducing gas, it means with carbon monoxide as in reaction (3), (4) and (4). At temperatures over $950-1000{ }^{\circ} \mathrm{C}$ coke carbon decomposes carbon dioxide according to the Boudouard reaction. Direct reduction represents then a complete reaction indicated according to Hess's law. Wustit reduction is then specified as follows:

$$
\begin{array}{lr}
\mathrm{FeO}+\mathrm{CO} \rightarrow \mathrm{Fe}+\mathrm{CO}_{2} & +17.13 \mathrm{~kJ} \\
\underline{\mathrm{CO}_{2}}+\mathrm{C} \rightarrow 2 \mathrm{CO} & -172.47 \mathrm{~kJ} \\
\mathrm{FeO}+\mathrm{C} \rightarrow \mathrm{Fe}+\mathrm{C} & -155.34 \mathrm{~kJ}
\end{array}
$$

A French metallurgist Grüner introduced a definition of "ideal run of the blast furnace". He proclaimed that total rejection of direct reduction $\left(r_{i}=1\right)$ would enable to reach minimum carbon consumption because indirect reduction would not consume heat during its run (on the contrary it produces a lower amount of the heat) in comparison with heavily endothermic direct reduction. Discussions on "ideal run of the blast furnace" have continued up till now. The conclusions are important (Babich et al., 2008).

A comparison of reactions (5) and (8) shows that direct reduction is more favourable from the point of view of deoxidising factor consumption but it brings heat deficiency. Blast-furnace coke is a resource both of the heat and of the reducing gas. To cover heat demand for direct reduction it is necessary to burn carbon in front of tuyeres which generates a certain amount of CO. Generation of a greater amount of $\mathrm{CO}$ than necessary for reduction purposes results in its loss with top gas. On the other hand production of necessary amount of reducing gas for indirect reduction can result in the production of excessive amount of heat. Therefore, providing minimum coke consumption requires an optimum balance between heat and reduction requirements, or in other words, between the proportion of direct and indirect reduction to complete reduction. These problems are illustrated in Figure 1 (Babich et al., 2008).

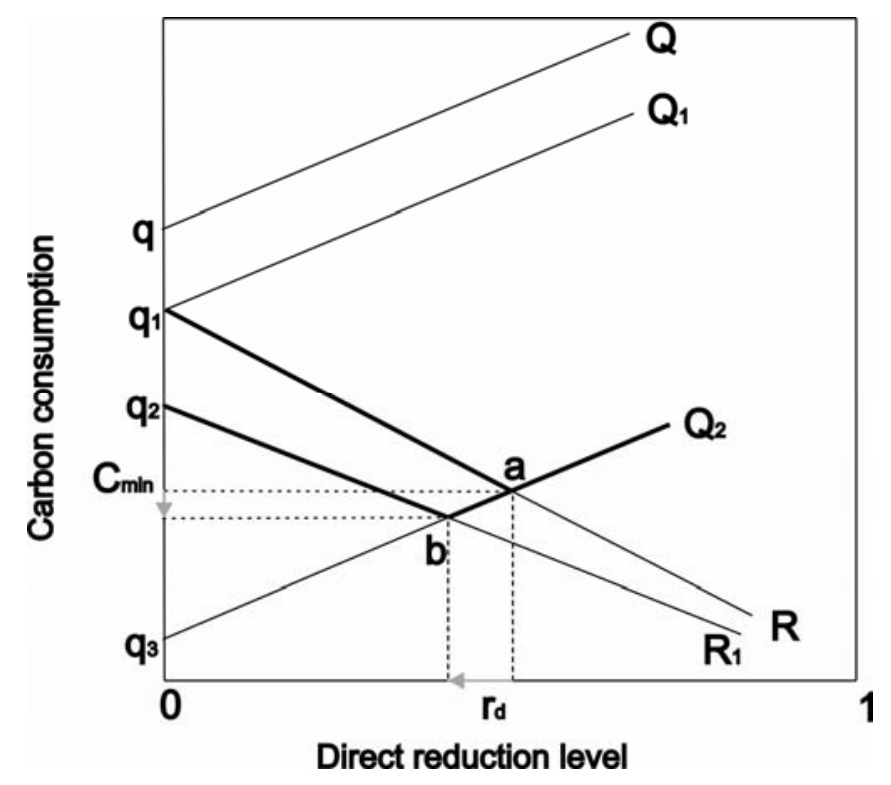

Fig. 1. Graphic representation of relation of limit carbon consumptions per heat and reduction

Line $Q$ in Figure 1 represents carbon consumption as a heat resource and line $R$ represents carbon consumption as a reducing factor. A lower level of direct reduction $\left(r_{d}\right)$ also requires lower carbon consumption as a heat resource in the case presented with line $Q$. The highest carbon consumption as a deoxidising factor $\left(R\right.$ at $r_{d}=0$ ) refers to the lowest carbon consumption for heat (point $q$ ) at the same time. 
Carbon consumption for providing function of reducing factor is higher (point $q_{1}$ ) than in case of $r_{d}=0$. As carbon consumption for heat needs follows line $\mathrm{Q}_{1}$ then $\mathrm{q}_{1}$ value refers to Grüner's "ideal run of the blast furnace". Nowadays conditions of the process have considerably changed in comparison with Grüner's times. Treated iron ore and a decrease of slag specific amount at present an increase of blast temperature and a decrease of furnace heat losses result in movement of the heat line $Q$ to lower values of carbon consumption for heat. When the decrease is up to the level characterised with $Q_{2}$ line, carbon consumption for heat $q_{3}$ is small only at indirect reduction and it is not enough to provide thermodynamically required much higher carbon amount characterised with point $q_{1}$.

The real area of carbon consumption providing both reduction and heat needs of the process lays over the broken line $Q_{2}$ and $q_{1}$. Minimum carbon specific consumption is then reached at a certain optimum level of direct reduction referring to the point of intersection of lines $Q_{2}$ and $R$.

Nowadays, there is an endeavour to replace a certain part of blast-furnace coke by injection of alternative deoxidising factors containing hydrogen. Carbon amount needed for reduction is decreased further on in this way and moves, as a result, from line $R$ to line $R_{1}$. A real reduction area lays then over the broken line $Q_{2}$ and $q_{2}$ and minimum carbon specific consumption is reached at a lower proportion of direct reduction (shift from the point $a$ to the point $b$ ).

Feedstock quality (iron content, acidity, and grain), parameters of blast (temperature, amount of alternative deoxidising factors and their composition) and gas flow control are factors determining temperature and reduction demands of the process and they influence the value of direct reduction level. Approx. $50 \%$ of coke and $20-30 \%$ of injection of alternative fuels are involved in direct reduction.

From the original Grüner-Ramm's diagram (see Fig. 2) follows that only at a proportional decrease of coke consumption at the expense of a decrease of direct reduction level of wustit $r_{d}$ at a simultaneous decrease of the amount of reducing gas and improvement of its use (points 1 and 2) and at the expense of a decrease of carbon consumption as a heat resource (points 1 and 3), it is possible to reach the minimum possible coke consumption if the initial level of $r_{d}$ rate is kept (point 1). It is accompanied with a certain increase of fuel consumption (point 2) or with an increase of the direct reduction level (point 3 ) which actually means that reduction potential of gas is not used.



Fig. 2. Graphic analysis of the possibility of decrease of carbon specific consumption 
As indirect reduction is applied in the first phase of blast-furnace process the scope of its course is essentially decisive for the resulting mutual proportion of both types of reductions. Therefore, kinetic simulation of indirect reduction of iron oxides plays a key role. Mutual dependence between the proportion of direct reduction and resulting carbon reducing factor consumption represents then the requirement for real minimum provision of the reduction process by this fuel/reducing factor.

Model considerations came out from a simplified idea of indirect reduction with carbon monoxide in the isothermal area of ore feedstock column. In the first solution the Boudouard reaction was not taken into account under an assumed temperature level of an isothermal area. This also refers to reduction reactors of alternative methods of iron production where there is no solid carbon in the reaction area.

According to the general model, this concept results from an idea of counter-flow of ore feedstock and reducing gas in the space of vertical cylinder with a base of unit area (Fig. 3). Movement of both phases - ore feedstock and reducing gas - occurs in the direction of the cylinder axis against itself. Cylinder axis is parallel to coordinate axis z. Reducing gas goes into the cylinder on horizon with coordinate $z=0$.



Fig. 3. Model scheme of counter-flow of feedstock and gas

On the other hand, a mixture of iron oxides $\left(\mathrm{Fe}_{2} \mathrm{O}_{3}\right.$ a $\left.\mathrm{Fe}_{3} \mathrm{O}_{4}\right)$ enters into the cylinder on horizon $z=L$ and step by step reduction occurs as per the following scheme:

$$
\begin{aligned}
& i=1 \quad i=2 \quad i=3 \quad i=4 \\
& \mathrm{Fe}_{2} \mathrm{O}_{3} \rightarrow \mathrm{Fe}_{3} \mathrm{O}_{4} \rightarrow \mathrm{FeO}_{1.05} \rightarrow \mathrm{Fe}
\end{aligned}
$$

Reduction speed is proportional to the product of kinetic constant $k_{i}$, Fe concentration in the particular $C_{i}$ oxide and the difference of $\mathrm{CO}$ concentration in reducing gas against equilibrium concentration $\left(X-X_{r i}\right)$. After limiting transition to an infinitely small height $\mathrm{dz}$ and an infinitely small time $d t$, it is possible to derive a hydrologic equation for $i$-oxide

$$
\frac{\partial C_{i}}{\partial t}-\frac{v_{p}}{1-\varepsilon} \cdot \frac{\partial C_{i}}{\partial z}=-k_{i} C_{i}\left(X-X_{r, i}\right)+k_{i-1} C_{i-1}\left(X-X_{r, i-1}\right)
$$

where: $v_{p}$ descending speed of feedstock; $\varepsilon$ porosity of ore feedstock.

Iron oxidation level in the feedstock is defined: 


$$
Y=1.5 C_{1}+1.33 C_{2}+1.05 C_{3}
$$

Material balance in the cylinder with the elementary height $\Delta z$ takes into account inlet and outlet flow and accumulation of carbon monoxide. It is valid that

$$
\varepsilon \rho_{g} \cdot \frac{\partial X}{\partial z}+v_{g} \rho_{g} \cdot \frac{\partial X}{\partial z}=(1-\varepsilon)-\rho_{p} \cdot \frac{\partial Y}{\partial t}-v_{p} \rho_{p} \cdot \frac{\partial Y}{\partial z}
$$

where: $\rho_{g}$ reducing gas density; $v_{g}$ non-composite speed of reducing gas; $\rho_{p}$ proportion of all iron in volume unit of ore feedstock. This Equation (12) completes the system of Equations (10) for $i=1, \ldots ., 4$ to a complete system of partial differential equations that can be theoretically solved for particular initial and edge conditions.

\section{SIMULATION OF THE REACTION STEPS}

Individual simple indicators of reducibility determined by laboratory tests do not meet the requirement for complex and universal characteristics of reducing properties. They define reducibility of kinetic constant of reduction speed for a selected temperature in a more complex and universal way.

Data on overall reduction can be acquired from the record of time decrease of oxygen mass in feedstock during reduction. An example of oxygen reduction during ordinary determination of reducibility by VÚHŽ method from three fractions is shown in Fig. 4.



Fig. 4. Oxygen decrease during reducibility test

The special difficulty lies in how to determine kinetic constants of reduction speed of individual oxides because it would be difficult to provide a separate course of their reduction. To determine individual kinetic constants (coefficients of reduction speed) for oxides a mathematical procedure was developed using results of usual isothermal reducibility tests with a gaseous mixture of $\mathrm{CO}-\mathrm{N}_{2}$. The main goal was to use the designed mathematical model of iron reduction with gas for simulation and analysis of reduction in a reducing stack.

A general version modified with the respect to specific testing conditions was designed for analysis and interpretation of results of laboratory reducibility tests. Laboratory reducibility tests are usually conducted at a stationary layer where $v_{p}=0$. In comparison with the real reduction stack the height of a sample layer is very low during laboratory reducibility tests and the amount of reducing gas toward a sample is very high. Consequently, a hypothesis can be formulated that besides sample height in testing retort the differences in levels of feedstock oxidation and reducing gas during reduction at an appropriate instant of time are irrelevant. Then, also derivations according to the layer height can be considered to be zero with regard to the other equation terms. 
Equation (10) is simplified to the following formula:

$$
\frac{d C_{i}}{d t}=-k_{i} C_{i}\left(X-X_{r, i}\right)+k_{i-1} C_{i-1}\left(X-X_{r, i-1}\right)
$$

In this way a system of common linear differential equations from a general model is derived which can be solved analytically. An analytic solution enables to express in the time gradually changing level of iron oxidation as a function of individual kinetic constants:

$$
\begin{gathered}
C_{1}=f_{1}\left(t, k_{1} \ldots\right) \\
C_{2}=f_{2}\left(t, k_{1}, k_{2} \ldots\right) \\
C_{3}=f_{3}\left(t, k_{1}, k_{2}, k_{3} \ldots\right)
\end{gathered}
$$

An analytic solution for $C_{1}$ :

$$
C_{1}=C_{\mathrm{Fe}_{2} \mathrm{O}_{3}, 0} \cdot e^{-k_{\mathrm{Fe}_{2} \mathrm{O}_{3}} \cdot\left(X_{0}-X_{r, \mathrm{Fe}_{2} \mathrm{O}_{3}}\right) \cdot t}
$$

An analytic solution for $C_{2}$ :

$$
\begin{aligned}
C_{2} & =\left[C_{\mathrm{Fe}_{3} \mathrm{O}_{4}, 0}-\frac{C_{\mathrm{Fe}_{2} \mathrm{O}_{3}, 0} \cdot k_{\mathrm{Fe}_{2} \mathrm{O}_{3}} \cdot\left(X_{0}-X_{r, \mathrm{Fe}_{2} \mathrm{O}_{3}}\right)}{k_{\mathrm{Fe}_{3} \mathrm{O}_{4}} \cdot\left(X_{0}-X_{r, \mathrm{Fe}_{3} \mathrm{O}_{4}}\right)-k_{\mathrm{Fe}_{2} \mathrm{O}_{3}} \cdot\left(X_{0}-X_{r, \mathrm{Fe}_{2} \mathrm{O}_{3}}\right)}\right] \cdot e^{k_{\mathrm{Fe}_{3} \mathrm{O}_{4}} \cdot\left(X_{0}-X_{r, \mathrm{Fe}_{3} \mathrm{O}_{4}}\right) \cdot t}+ \\
& +\frac{C_{\mathrm{Fe}_{2} \mathrm{O}_{3,0} \mathrm{O}} \cdot k_{\mathrm{Fe}_{2} \mathrm{O}_{3}} \cdot\left(X_{0}-X_{r, \mathrm{Fe}_{2} \mathrm{O}_{3}}\right)}{k_{\mathrm{Fe}_{3} \mathrm{O}_{4}} \cdot\left(X_{0}-X_{r, \mathrm{Fe}_{3} \mathrm{O}_{4}}\right)-k_{\mathrm{Fe}_{2} \mathrm{O}_{3}} \cdot\left(X_{0}-X_{r, \mathrm{Fe}_{2} \mathrm{O}_{3}}\right)} \cdot e^{k_{\mathrm{Fe}_{2} \mathrm{O}_{43}} \cdot\left(X_{0}-X_{r, F e_{2} \mathrm{O}_{3}}\right) \cdot t}
\end{aligned}
$$

and then analogically also for $C_{3}$.

As it follows from the analytic solution the oxidation level also depends on the initial composition of a reduced sample and on the real and balanced composition of reducing gas. These data as model input data have to be always available. To simplify extensive numeric calculations a further assumption was made that before reduction there is no free iron in the sample and dyad iron is bound only in $\mathrm{Fe}_{2} \mathrm{O}_{3}$. For calculation of initial values of concentrations $C_{i}$ is expected accordingly $C_{3}=C=0$.

The total level of iron oxidation in the sample reduction is determined from concentrations of individual oxides according to Equation (9). In case that the presented model sufficiently reproduces reality, the time course of a calculated level of iron oxidation $Y\left(t_{j}\right)$ is ideal to be referred to experimentally found course of iron oxidation level $Y_{j}$, which can be explicitly derived from a decrease of sample feedstock during reduction.

Of course, to calculate time course of $Y\left(t_{j}\right)$ value, it is necessary to know the values of kinetic constants $k_{1}, k_{2}$ and $k_{3}$, which can be acquired by minimisation of criterion $\Theta$ defined in the following Equation (17)

$$
\Theta\left(k_{1} k_{2}, k_{3}\right)=\sum_{j}\left(Y_{j}-Y\left(t_{j}\right)\right)^{2}
$$

where: $j=i-1$ or $j=i$.

Minimisation of criterion $\Theta$ regarding the above mentioned variables determines the most probable values of $k_{1}, k_{2}$ and $k_{3}$.

The procedure enabled relatively simple determination of kinetic constants of reducibility and created an essential condition for implementing the proper reduction kinetic model both in the blast furnace and in reducing reactors of alternative technologies of iron production. 


\section{KINETIC MODEL OF REDUCTION OF OXIDES IN REDUCING STACK OF IRON PRODUCTION UTILITY}

The following part of reduction model represents the kinetic calculation of (quasi)kinetic constants $k_{1}$, $k_{2}, k_{3}$ for simulation of oxide reduction in the reduction stack of iron production utility.

In spite of its empiricism, the model would sufficiently reflect also the physical principles of the process. It is especially necessary for the model to correctly describe the influence of various compositions of reduction gas as well as the influence of grain size of reduced oxides. When these goals are reached, kinetic constants acquired through reducibility test and characterising appropriate ore feedstock will be applicable also for mathematic evaluation of reduction course in an appropriate reduction utility and thereby also for determination of optimum response from the point of view of individual criteria (use of reducing gas, utility output, etc.).

The problem of counter-flow reduction of iron oxides is described on the basis of a presumption of "piston run" of both gaseous and solid reaction components. The presumption of "piston run" is well met at least during the first approach as far as gases are concerned. Gases penetrate through feedstock at high speed and the height of the layer is also considerable.

In case of feedstock, deviations from the ideal downward motion are obviously higher because of radial dependence of the sliding speed of particles. Also the layer in not homogenous because of a layered arrangement of feedstock during charging and subsequent segregation. But simplifying presumptions are considered to be reasonable at the existing stage of knowledge and the stipulated model would make a background for further development by introducing more realistic elements into a description of an actual layer.

The presumption of time-stable reduction course enabled to eliminate material balances (14) and (13) derivation per time from the previous equations. A system of balance equations after modification has the following form

$$
\begin{gathered}
-\frac{v_{p}}{1-\varepsilon} \cdot \frac{d C_{i}}{d z}=-k_{i} C_{i}\left(X-X_{r, i}\right)+k_{i-1} C_{i-1}\left(X-X_{r, i-1}\right) \\
v_{g} \cdot \rho_{g} \cdot \frac{d x}{d z}=-v_{p} \cdot \rho_{p} \cdot \frac{d y}{d z}
\end{gathered}
$$

In spite of this simplification, non-linearity of the system of equations and the type of edge conditions do not allow to find a simple analytic solution. Therefore, a numeric method of solution using iteration methods was elaborated.

The requirement for a simple and logical presentation of input data for calculations requested a modification of mentioned equations. From the gas material balance Equation (19) follows that the level of iron oxidation $Y$ depends linearly on the concentration of reducing gas $X$. The straight line with inclination determined by quotient $\left(v_{g} \cdot \rho_{g} / v_{p} \cdot \rho_{p}\right)$ is then functionally dependent on the co-ordinates $X, Y$. But it is more suitable to use co-ordinates introduced by Rist for reduction description in blast furnace for more clear illustration. Instead of carbon monoxide concentration $X$ level of carbon oxidation in reducing gas $X^{*}$ is used which is connected with carbon monoxide concentration $X$ by relation $X^{*}=2-X$. The straight line characterising this so far linear dependence is then called operational one in the co-ordinates $X^{*}, Y$.

An inclination of the operational straight line in the co-ordinates modified in this way defines specific consumption of reducing gas. The period of feedstock hold-up $\mathrm{U}$ is defined by the quotient of height of feedstock column in the area of indirect reduction $\mathrm{L}$ and descending feedstock speed $v_{p}$. 
Data on the initial feedstock composition $C_{i}$ on horizon $z=L$, data on specific consumption of reducing gas (CS) as well as data on the presumed period of feedstock hold-up in the zone of indirect reduction and last but not least the already mentioned characteristics of feedstock reducibility stated by kinetic constants $k_{1}, k_{2}, k_{3}$ are input data for numeric calculations. Concentration profiles of individual iron oxides as well as carbon monoxide beside the height of reaction area $L$ are the result of a numeric solution, see Fig. 5.



Fig. 5. Concentration profiles in reaction area of indirect reduction

From the point of view of further use the level of iron oxidation $Y_{R D}$ on horizont $z=0$ is the most significant result. The level of iron oxidation is related to the level of wüstit indirect reduction by a simple relation

$$
r_{d}=\frac{Y_{R D}}{1.05}
$$

and it is applied during the calculation of the so-called " $\omega$ parameter"

$$
\omega=Y_{R D}+C S \cdot\left(1-X_{r, 3}\right)-1.05
$$

The parameter indicates the difference between oxidation levels of feedstock and wüstit in the area of feedstock column where reducing gas has a structure referring to the equilibrium of wüstit and iron.

\section{FUNCTIONAL EXAMPLE OF DETERMINATION OF KINETIC CONSTANTS FROM THE RESULTS OF EXPERIMENTAL TESTS OF REDUCIBILITY AND SUBSEQUENT USE DURING SIMULATION OF METALLURGICAL PROCESSES OF IRON PRODUCTION}

The initial testing of reducibility was carried out at the test-room of VÚHŽ Dobrá (Research Institute of iron - making, Dobrá). Parameters of the measurements are presented in Table 1.

The Levenberg-Marquardt method was used for optimisation of the function $\mathrm{F}\left(k_{1}, k_{2}, k_{3}\right)=\Sigma\left(Y_{j}-Y\left(t_{j}\right)\right)^{2}$. The optimisation was programmed in $\mathrm{C}++$ language using MATLAB mathematical library. Calculations were made for different initial estimations of effective kinetic constants and convergence occurred in all the cases. Supplementary statistic data such as matrices of covariance and correlation of these constants are also results of calculations. Calculated kinetic constants are an important starting 
parameter during simulation of reduction processes of iron oxides in the stack of blast furnace. Fig. 6 shows an example of inputs for a calculation of kinetic constants, including the results of model calculation.

Table 1. Characteristics of reducibility measurements

\begin{tabular}{|l|l|}
\hline Sample weight & $1000 \mathrm{~g}$ \\
\hline Temperature & $900{ }^{\circ} \mathrm{C}$ \\
\hline Composition of reducing gas & $40 \% \mathrm{CO}, 60 \% \mathrm{~N}_{2}$ \\
\hline Equilibrium gas concentrations & $X_{r, 1}=0.01 ; X_{r, 2}=0.198 ; X_{r, 3}=0.675$ \\
\hline
\end{tabular}

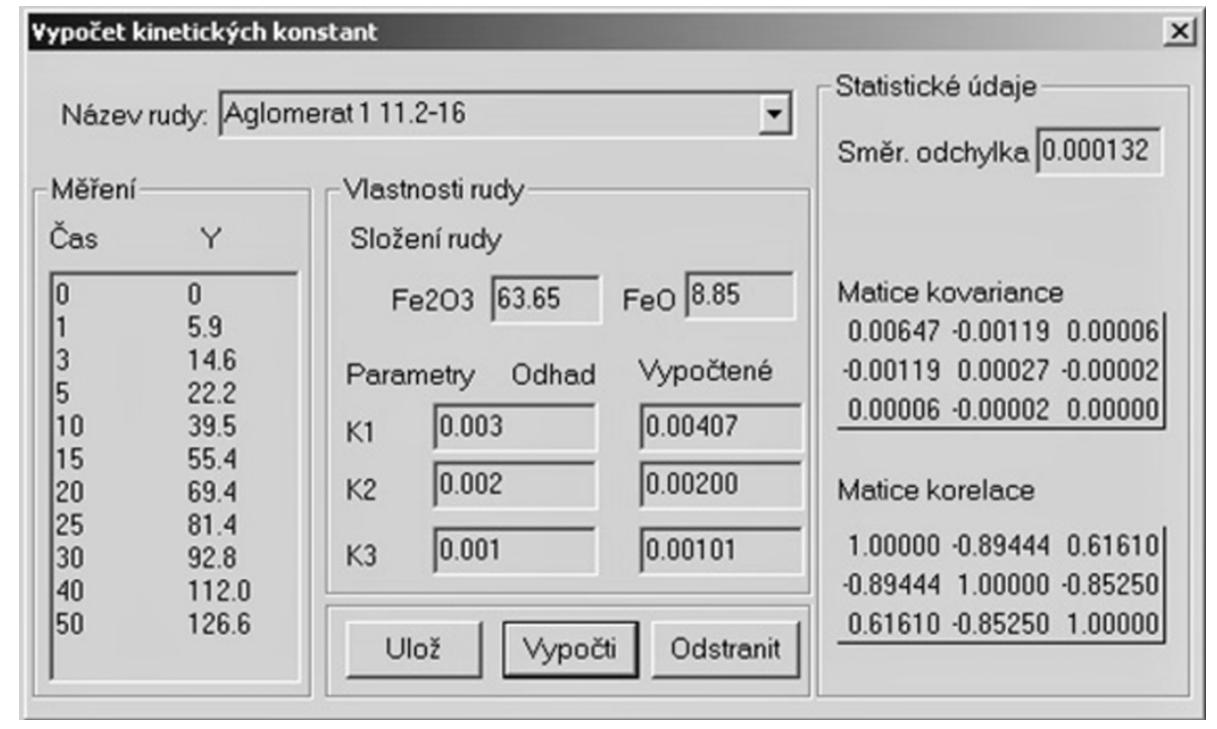

Fig.6. Example of dialog box for calculation of kinetic constants from the reducibility test used in the Czech version of the model

Results of reducibility test were used for simulation of different model options of indirect reduction of iron oxides. A proportion of direct reduction on total reduction range - direct reduction level $r_{d}$ forms an output of this simulation. The proportion of direct/indirect reduction ideally represents the proportion of wüstit in reduced feedstock when the area relative height of indirect reduction is zero. Below wüstit reduced feedstock the Boudouard reaction starts (Jeschar and Bittner, 1986).

First of all, the kinetic model of reduction of iron oxides can be particularly applied during simulation of reduction course in the blast furnace. Using approaches applied by Rist during graphic analysis of reduction and heat operation of a blast furnace, results calculated using the kinetic model were transformed into CDR - diagram already mentioned in the introduction where a new limiting curve acquired in this way characterises reachable "kinetic limit" and carbon/fuel consumption taking into account the real current reducibility of blast-furnace ore feedstock (see Fig. 7). From the point of view of enthalpy balance, heat developed during carbon gasification to reducing gas will cover also necessary heat needs of the process. Carbon needed for heat (heat limit) also depends significantly on the level of direct reduction.

In comparison with the original form of CDR - diagram, the version presented in Fig. 7 shows not theoretic but rather actual limits of minimum specific consumption of reduction gas that take into account actual feedstock reducibility and that can be reached only through an appropriate use of reduction gas. 


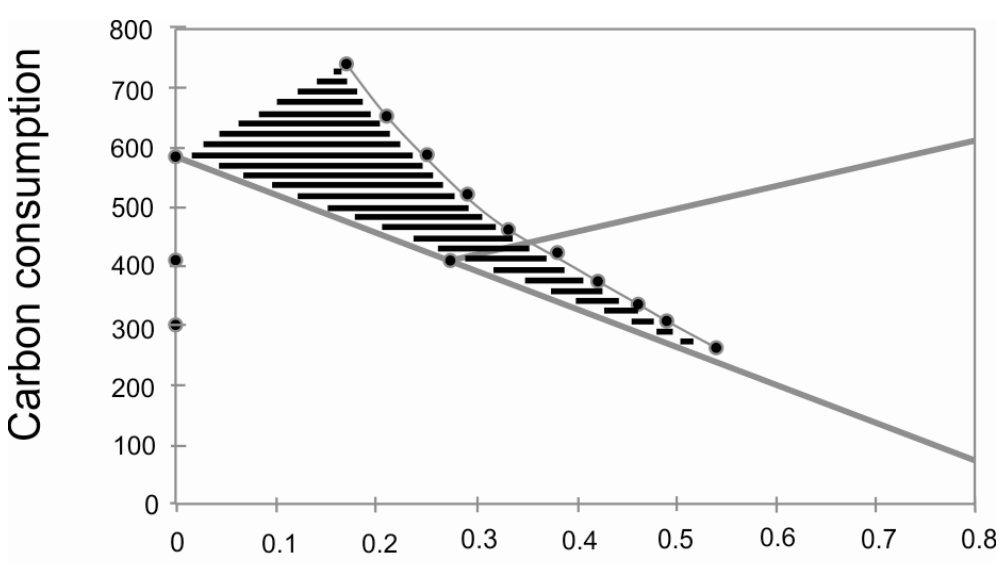

Direct reduction degree, $\mathrm{rd}_{\mathrm{d}}$

Fig.7. Determination of kinetic and heat limits of carbon consumption for different process conditions (modified CDR-diagram)

The mathematic model based on indirect reduction describes well reduction course in the area of blast furnace where speed of the Boudouard reaction is small. However, this model can also be successfully applied for simulation of reduction process of the so-called direct iron production (see Fig. 8) where coke is not used or for estimation of the proportion of direct/indirect reduction with processes of melting reduction, see Fig. 9.

First of all, the level of ore feedstock metallisation metallisation reached at the feedstock output from the reduction stack at its bottom part is important for the evaluation of simulation results of these alternative processes.

Calculations of concentration profiles can be carried out for different specific consumptions of reduction gas. Calculations then enable to predict the metallisation level (pre-reduction) for various kinds of feedstocks (ore, pellets, agglomerates) coming into question. As the model also enables simulation of different reduction duration and/or speed of feedstock decline in the stack the application practicability of various feedstock kinds can also be evaluated from the point of view of aggregate productivity (Bilik, 1999; Kozaczka and Kolat, 2010).

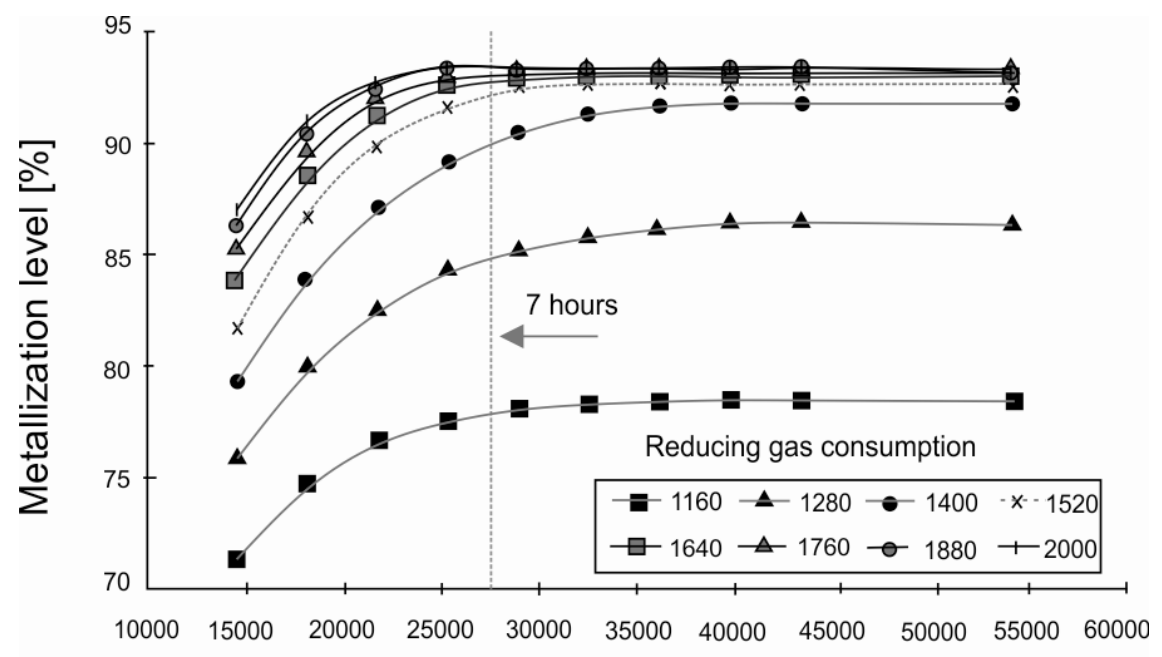

Duration of charge keeping in reduction stack [s]

Fig.8. Reduction course and reducing gas consumption in the stack of reduction aggregate 
Fig. 8 represents quantitative relations among the quality of sprayed metal product (metallisation level), aggregate productivity (duration of feedstock keeping in reduction stack) and specific consumption of deoxidising factor. From the indicated example of graphic review it follows that for it reviewed ore a high level of metallisation (above $90 \%$ ) can be reached when it is kept in a reactor for a period of approx. 7 hours with the consumption of gaseous deoxidising factor of approx. $1800 \mathrm{~m}^{3}$ per ton of the product.

Next, Fig. 9 shows a comparison of an alternative technology of COREX (FINEX) heat reduction with a classic blast furnace with an application of analytic CDR diagram. The figure shows a diagram area with a high proportion of indirect reduction. In case of blast furnace deoxidising factor (coke) consumption declines with a decreasing proportion of indirect reduction because direct reduction does not require any surplus of deoxidising factor. This trend continues up to the proportion of indirect reduction of iron oxides of approx. $75 \%$, in point $\mathrm{M}$ then, the function of fuel consumption begins to be limiting for total coke consumption, mainly heat demands of endothermic direct reduction (Tůma, et al., 1986). But carbon consumption for indirect reduction during an actual process is rather higher and it is characterised by working point $P$. The total hatched surface represents then the existing reserve in comparison with thermodynamic minimum. The kinetic model enables further specification of actual possibilities of partial run out of this reserve up to practically reachable minimum of deoxidising factor consumption. The model takes into account actual reducibility of used ore feedstock (two-side hatched area) during this determination.

The situation with COREX (FINEX) process is slightly different in comparison with the blast furnace. The lines of theoretic and practical limiting consumptions of deoxidising factor intersect in the immediate vicinity of $100 \%$ proportion of indirect reduction (point $M^{\prime}$ and $P^{\prime}$ ) and in case of no prereduction of ore feedstock to the needed level (approx. $90 \%$ ), a considerable increase of coal specific consumption occurs as a result of explosive heat demands of the process.

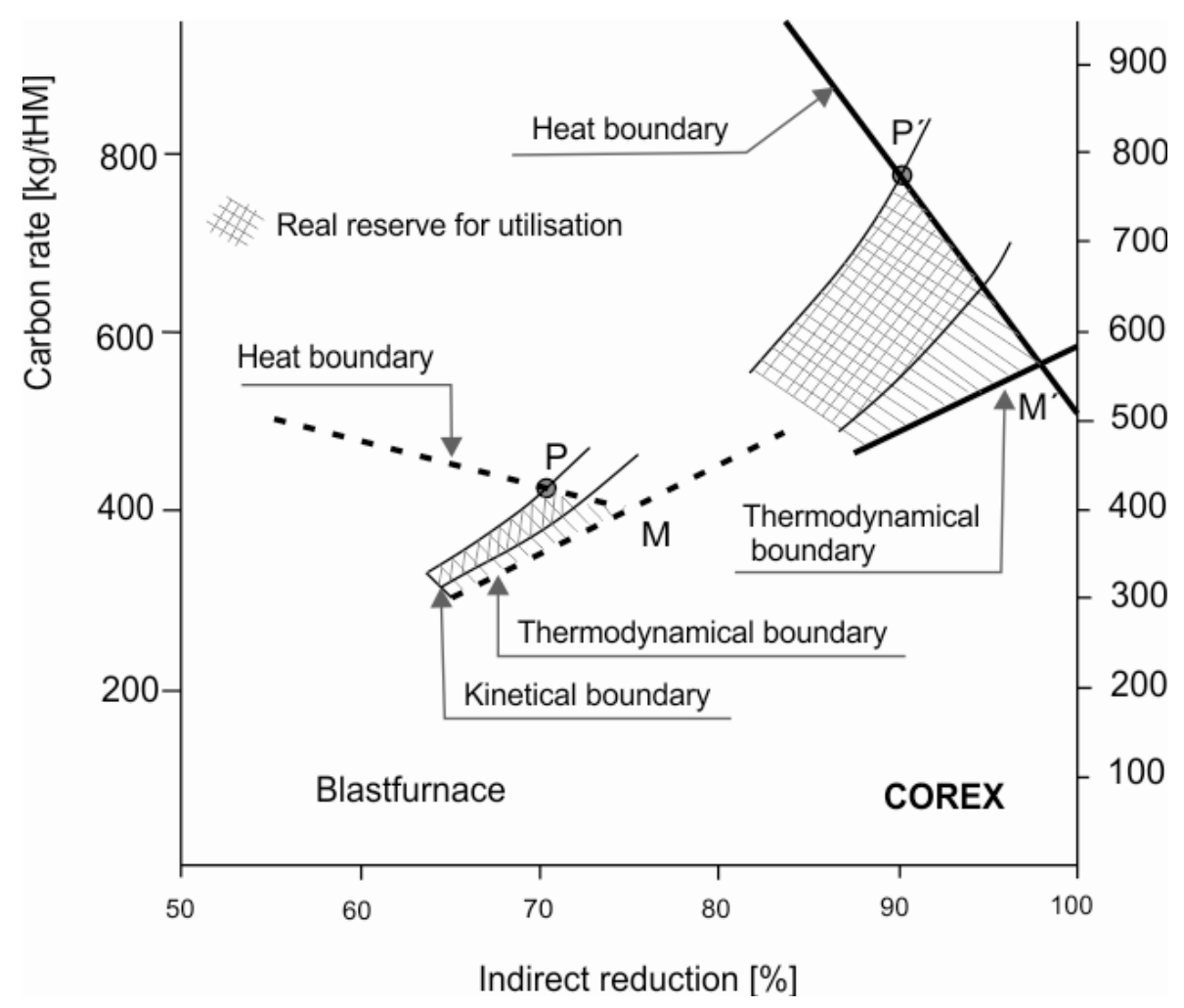

Fig.9. Evaluation of proportions of both reduction forms and schematic determination of technological reserve during blast-furnace process and process of COREX - FINEX melting reduction 
This much steeper increase of heat limit is caused by the technological conception of the process, which enables to use only a small part of heat from the total energetic input of this alternative technology to cover direct reduction demands. Prognosis of reduction course and results obtained using the kinetic model can therefore have a considerable influence on the evaluation of deoxidising factor/fuel consumption and thereby also on the prognosis of energetic efficiency of the new technology (Back and Bilik, 1997; Roubíček and Buchtele, 2002). In blast furnace department a decrease of total costs of production is possible mainly by a decrease of the costs of fuel (Kardas et al., 2007).

\section{CONCLUSIONS}

As it follows from present trends of metallurgy development in the Czech Republic as well as in Europe, we can expect that blast-furnace technology for preparation of input feedstock for steelworks will play a decisive role in the next two decades further on. To increase the level of control of energetically extra demanding blast-furnace process VŠB - TU Ostrava has developed a system of models where approaches of process (chemical) engineering were applied to a wider extend, mainly thermodynamic and kinetic reduction model of ore feedstock. Practical application of models enables to determine particular limits of heat conditions and kinetics of reduction. This also enables a more objective assessment of the impact of the prepared innovations in the sphere of iron production. Therefore, currently more complex model for more precise prognosis of proportion of direct and indirect reduction is being developed in VŠB - Technical University of Ostrava.

This work was supported by the Czech Ministry of Education, Youth and Sports, research project MSM 6198910019 and project CZ.1.05/2.1.00/03.0069.

\section{SYMBOLS}

$\begin{array}{ll}r_{i} & \text { indirect reduction } \\ r_{d} & \text { direct reduction } \\ Q ; Q_{1} ; Q_{2} & \text { carbon consumption as a heat resource } \\ q ; q_{1} ; q_{2} ; q_{3} & \text { characterised amount of carbon } \\ R ; R_{1} & \text { carbon consumption as a reducing factor } \\ \Delta z & \text { elementary height } \\ k_{i} ; k_{i-1} ; k_{1 ;} ; k_{2} ; k_{3} & \text { kinetic constant } \\ C_{i} & \text { concentration } \mathrm{Fe} \text { in the particular } C_{\mathrm{i}} \text { oxide } \\ \left(X-X_{r i}\right) & \text { difference of } \mathrm{CO} \text { concentration in reducing gas against equilibrium } \\ v_{p} & \text { descending speed of feedstock } \\ Y & \text { iron oxidation level in the feedstock } \\ C_{1} ; C_{2} ; C_{3} & \text { concentrations of individual oxides } \\ v_{g} & \text { non-composite speed of reducing gas } \\ X & \text { level of carbon oxidation in reducing gas } X^{*} \\ C S & \text { specific consumption of reducing gas } \\ Y_{R D} & \text { level of iron oxidation } \\ X_{r, 1} ; X_{r, 2} ; X_{r, 3} & \text { equilibrium gas concentrations }\end{array}$

Greek symbols

$\varepsilon \quad$ porosity of ore feedstock

$\rho_{g} \quad$ reducing gas density, $\mathrm{kg} / \mathrm{m}^{3}$ 
$\rho_{p} \quad$ proportion of all iron in volume unit of ore feedstock, $\mathrm{kg} / \mathrm{m}^{3}$

$\omega \quad$ parameter difference between oxidation level of feedstock and wüstit

Abbreviation

ÚTZCHT ČS AV Ústav teoretických základů chemické techniky České akademie věd

VÚHŽ Dobrá Výzkumný ústav hutnictví železa Dobrá

\section{REFERENCES}

Brož L., 1975. Theoretical basics of ironmaking. $1^{\text {st }}$ edition, SNTL/ALFA, Praha, 162 - 175.

Corre C.L., 1977. Modele mathematique de la reduction a contre / courant des oxydes de fer contenus dans les agglomeres. C.I.T., 34, 3-22.

Tůma J., Drabina J., Honza O., Staněk V., Moravec P., 1988. Using a mathematical model for evaluating the reductibility of iron bearing raw materials. Hutnické listy, 43, 228-233.

Rist A., Meysson N., 1964. Recherche graphique de la mise on mille minimale du haut fourneau a faible temperature du vent. Rev. de Metall. 2, $121-145$.

Bilík J., Schützenhöfer W., Hiebler H., 1998. Einsatz der mathematischen Modellierung in der Reduktionsmetallurgie. Berg - und Hüttenmännische Monatshefte, 143 Jg., 166 - 169.

Bilík J., Schützenhőfer W., 1999. Smelting reduction of fine grained ores and coal. Hutnické listy, 54, 10-14.

Andronov V.N., 2007. Extraction of Ferrous Metals from Natural and Secondary Resources, $1^{\text {st }}$ edition, SPbGTU, St. Petersburg, 52 - 56.

Babich A., Senk D., Gudenau H.W., Mavrommatis K.Th., 2008. Ironmaking. $1^{\text {st }}$ edition, Wissenschaftswerlag Mainz, Aachen, 181 - 200.

Tůma J., Prouza M., Pokorný M., 1986. Control of blast furnace operation. Hutnické aktuality, 27, 50 - 57.

Kozaczka J., Kolat P., 2010. Exergy and its applications. $1^{\text {st }}$ edition, TANT Publisher, Tarnow, 96 - 112.

Jeschar R , Bittner H.G., 1986. A theoretical model coupling kinetics of ore reduction and coke gasification in blast furnaces. 1st. European Ironmaking Conference, 1986.

Bilík J., 1999. Kinetics of wüstite reduction together with coke gasification by Bourdouard's reaction for operational results prediction. Conference on Iron and Steelmaking, Hradec nad Moravicí, the Czech Republic, 19 - 22 September 1999, 64 -67.

Back E., Bilík J., 1997. Smelting reduction as an alternative of blast furnace. Hutnické listy, 12, 3 - 9.

Roubíček V. Buchtele J., 2002. Coal - resources, processes, utilization. $1^{\text {st }}$ edition, Montanex, Ostrava, 52 - 56.

Kardas E., Konstanciak M., Prusak M., Budzik R. 2007. Selected elements of economics of blast furnace process. Acta Metalurgica Slovaca, 13, 497-501.

Received 10 November 2011

Received in revised form 17 December 2012

Accepted 19 December 2012 